\title{
Isolation and Identification of Infection-Causing Bacteria in Dairy Animals and Determination of Their Antibiogram
}

\author{
Safia Arbab $\mathbb{D}^{1,2,3}$ Hanif Ullah ${ }^{1},{ }^{4}$ Weiwei Wang, ${ }^{1,2,3}$ Ka Li, ${ }^{4}$ Ali Akbar, ${ }^{5}$ \\ and Jiyu Zhang $\mathbb{B D}^{1,2,3}$ \\ ${ }^{1}$ Key Laboratory of Veterinary Pharmaceutical Development, Ministry of Agriculture, Lanzhou, China \\ ${ }^{2}$ Key Laboratory of New Animal Drug Project of Gansu Province, Lanzhou, China \\ ${ }^{3}$ Lanzhou Institute of Husbandry and Pharmaceutical Sciences, Chinese Academy of Agricultural Sciences, Lanzhou, China \\ ${ }^{4}$ West China School of Nursing, Sichuan University, Chengdu, China \\ ${ }^{5}$ Department of Microbiology, University of Balochistan, Quetta 87300, Balochistan, Pakistan
}

Correspondence should be addressed to Jiyu Zhang; infzjy@sina.com

Received 17 May 2021; Revised 1 November 2021; Accepted 12 November 2021; Published 8 December 2021

Academic Editor: Hadi Hashemi Gahruie

Copyright ( $\odot 2021$ Safia Arbab et al. This is an open access article distributed under the Creative Commons Attribution License, which permits unrestricted use, distribution, and reproduction in any medium, provided the original work is properly cited.

\begin{abstract}
Pathogens are always a threat to the livestock and domestic animals due to their exposure to the contaminated environments. The study was conducted to evaluation of the prevalence of Escherichia coli, Shigella spp., Salmonella spp., and S. aureus, in farm animals (cattle and buffalos). A total of $150(n=150)$ samples were collected from cattle and buffaloes, 60 samples from cows' and buffalo's teats milk, 30 of water samples, and 60 of fecal samples isolates from dairy farm animals, which may act as reservoir disseminating such pathogens. Farm hygiene, management, and milking procedure were listed through a questionnaire. The most common pathogens detected in this study was E. coli 88 (58\%) and S. aureus 81 (54\%), followed by Salmonella spp. 32 (21\%), and Shigella spp. $44(29 \%)$, respectively. During the antibiogram studies, the results revealed that the highest number of bacterial isolates showed resistance against ampicillin 50 (56.8\%), followed by ciprofloxacin $23(26.1 \%)$ and augmentin 22 (25\%) of Escherichia coli and ampicillin 49 (60.4\%), cefpodoxime 23 (28.3\%), and augmentin 20 (24.6\%) of S. aureus. In the case of Salmonella spp., the highest resistance was showed by amoxicillin $16(50 \%)$. In Shigella spp., the highest resistance was shown by ampicillin 16 (36.3\%), followed by cefpodoxime and ceftazidime $10(22.7 \%)$. The high frequency of isolates in this investigation with multiple antibiotic resistance ranges from 15. MARI \% value of S. aureus and E. coli 15 (12.5\%), followed by Salmonella and Shigella spp. ranges from 12 (10\%), suggesting the presence of various antibiotic-resistant bacteria as well as highly resistant bacteria. The mean \pm SD zone areas for the greater resistance are for E. coli and S. aureus, already known to be multiresistant, followed by Salmonella spp. and Shigella spp., when the zone areas are for the low resistance, and the findings determined that there was a little difference between S. aureus and E. coli.
\end{abstract}

\section{Introduction}

Dairy animals have always been one of the most studied animal species in terms of animal welfare [1], Nonetheless, there are important welfare issues that have yet to be resolved. Early weaning, which is still a common practice in the dairy business, has been one of those difficulties for the previous few decades [2].

Toxic metabolites from several pathogenic organisms living in milk and milk products may be present. Consumers get food poisoning when they eat such goods that are contaminated with these metabolites. Foodborne infection, on the other hand, is caused by ingesting viable pathogenic bacteria together with the food product [3]. The most common disease-causing bacteria in the milk are Mycobacterium bovis, Salmonella spp., Corynebacterium spp., Coxiella burnetii, Clostridium perfringens, Brucella, Staphylococcus spp., Yersinia enterocolitica, Campylobacter jejuni, Mycobacterium avium, Escherichia coli, Listeria spp., and coliforms [4, 5], as Gramnegative opportunistic environmental bacteria, have been classified. Mastitis caused by E. coli is typically sporadic, with symptoms ranging from mild to severe and even fatal [6]. 
Meal-borne infection, on the other hand, is caused by ingesting viable pathogenic bacteria along with the food [3]. Total coliforms, E. coli, and other enteric bacteria in food, water, milk, and other dairy products in typically unclean conditions are reliable indications of fecal contamination. The presence of enteropathogenic and/or toxigenic microorganisms, which could pose a public health risk, is indicated by the recovery of E. coli from food [7]. According to public health agencies, these microbes are frequently linked to foodborne disorders and outbreaks [8]. The presence of these pathogenic bacteria in milk has become a major public health problem, particularly among individuals who continue to drink unpasteurized raw milk [9].

Antimicrobial drugs are used medically in animals and humans to treat bacterial infections, and they can also be added to commercial livestock and poultry feed at subtherapeutic dosages to promote growth [10]. During the twentieth century, antibiotics significantly reduced mortality associated with infectious diseases; however, their widespread and repeated use in animal farming has resulted in the emergence of bacterial multidrug resistance (MDR); as a result, the presence of antibiotic-resistant populations transforms infections that were once treatable into potentially life-threatening events. Antibiotics slow the growth of organisms without resistance mechanisms, but they have no or little effect on resistant infections, allowing them to survive and flourish in the host [11].

The purpose of this research was to determine the existence of infecting microorganisms and their antibiotic resistance patterns in the dairy farm environment, which could pose veterinary and public health risks by infecting animals and contaminating milk, water, and feces with antimicrobial-resistant avian strains as a result of poor milking hygiene.

\section{Materials and Methods}

2.1. Sample Collection. Samples were collected from different potential points considered to be associated with contamination (critical sampling points). The sampling points were the teat during milking, drinking water trough of lactating animals, and fecal samples. Overall, 150 samples were analyzed.

2.1.1. Milk Samples. A total of 60 milk samples from teats were collected from 20 cows and 15 buffaloes (30 hind and 30 teat). Milk samples were collected into sterile vials after washing, drying, and swabbing of teat ends with $70 \%$ ethyl alcohol and discarding of the first 3-4 streams of milk.

2.1.2. Drinking Water. 30 water samples $(50 \mathrm{ml}$ from each farm) were collected from the drinking troughs of the lactating animals into disposable sterilized test tubes. All samples were stored in an ice box until transported to the laboratory.
2.1.3. Fecal Samples. 60 fecal samples were collected from apparently healthy animals which showed no symptom of illness. Samples were collected with the use of sterile swab stick. The swab was transfer to its care, labeled, and taken to the laboratory.

\subsection{Bacterial Isolation and Identification}

2.2.1. Primary Culture. Nutrient broth, nutrient agar, MacConkey agar, eosin methylene blue (EMB) agar, Salmonella/Shigella agar, mannitol salt agar (MSA), and blood agar media were prepared, and swab samples were cultured aerobically and anaerobically over these media and incubated at $37^{\circ} \mathrm{C}$ for $24 \mathrm{~h}$. Following, the incubation colony characteristics were observed, and smears were prepared, for Gram's staining for cell morphology.

2.2.2. Subculturing and Identification. Purification of preliminary identified colonies was done by subculturing the isolated colonies on respective differential and selective media and repeated it several times. The purity of the samples was checked by examining stained smear. The pure culture was grown on agar slants, incubated at $37^{\circ} \mathrm{C}$ for $24 \mathrm{~h}$, and stored at $4^{\circ} \mathrm{C}$. The bacterial isolates were finally identified based on colony characteristic, microscopic morphology, biochemical properties such as catalase, oxidase, indole, coagulase, triple sugar iron, and Simmons Citrate Agar, and analytical profile index.

Round raised circular colonies on nutrient agar with Gram-positive reaction and round shape with bunches appearance under the microscope were presumed as Staphylococcus aureus and subcultured over MSA. Yellow colonies with catalase-positive reactions confirmed the presence of $S$. aureus.

Circular raised colonies with pink appearance on McConkey agar and rod-shaped bacteria with Gram-negative rection were subcultured over EMB agar, and the lactose-fermented colonies with green metallic sheen were considered and as conformed E. coli and subjected to analytical profile index for compete conformation.

Salmonella and Shigella spp. were subcultured on Salmonella/Shigella agar (SS agar), a Salmonella and Shigella spp.-specific agar. Typical colonies, such as Shigella, were detected as transparent or translucent colorless colonies on growth plates. The organisms were further confirmed with the help of Gram reactions, biochemical tests, and analytical profile index.

2.3. Antibiotic Susceptibility Test. Antibiogram potential of the isolates were determined according to the modified Kirby-Bauer disc diffusion method using Muller-Hilton agar following Clinical Laboratory Standards Institute guidelines (CLSI Performance Standards for Antimicrobial Susceptibility Testing) [12]. Each isolate was distributed on a separate nutrient agar plate, with an antibiotic disc dropped on top and cultured for 24 hours at $37^{\circ} \mathrm{C}$. Antibiotic discs were spread over the medium using a dispenser, and a sterile stick 
was used to gently tap each antibiotic disc onto the surface of the agar. The double-disc synergy test with cefotaxime and amoxicillin-clavulanate discs was used to screen for extended-spectrum $\beta$-lactamases (ESBL).

The 18 different antimicrobial agents ampicillin (AMC) $(10 \mu \mathrm{g})$, augmentin (AUG) $(30 \mu \mathrm{g})$, cefotaxime (CTX) $(30 \mu \mathrm{g})$, cefpodoxime (CP) $(10 \mu \mathrm{g})$, ceftazidime (CAZ) $(30 \mu \mathrm{g})$, amoxicillin (AMX) $(25 \mu \mathrm{g})$, cefuroxime (CXM) $(30 \mu \mathrm{g})$, ciprofloxacin (CPX) $(10 \mu \mathrm{g})$, tetracycline (TE) $(30 \mu \mathrm{g})$, streptomycin (STR) $(10 \mu \mathrm{g})$, gentamicin (GEN) $(10 \mu \mathrm{g})$, erythromycin (ERY) $(10 \mu \mathrm{g})$, nitrofurantoin (NIT), chloramphenicol (CHL) $(25 \mu \mathrm{g})$, and cotrimoxazole (STX) $(25 \mu \mathrm{g})$ were used, and results were recorded following the guidelines of CLSI [13].

\subsection{Multiple Antibiotic Resistance Index (MARI)} Determinations. MARI was determined using the formula MARI $=a / b$, where "a" represents the number of antibiotics that were successfully resistant and " $b$ " represents the total number of antibiotics employed in the study. An isolate with a MARI value of $0.2>$ indicates the presence of numerous antibiotic-resistant bacteria, as well as highly resistant bacteria [14].

2.5. Statistical Analysis. The graphical representation was performed using the program Microsoft Office Excel, 2007. Descriptive statistics of the data obtained from the study are given with mean, standard deviation, frequency, and percentage analysis.

\section{Results}

3.1. Isolated Bacterial Species. Dairy farms included in this study raised from 10 to 50 animals (cows and native buffaloes). Cow's age ranged from 10 years, while buffaloes were around. Overall, four bacterial targets were identified in different sampling collection points in this study. The bacteria identified and their prevalence rates were Escherichia coli 88 (58\%), Salmonella spp. 32 (21\%), Shigella spp. 44 (29\%), and Staphylococcus aureus 81 (54\%).

These are indicative of significant contamination of different sampling points. The most prevalent organism overall was E. coli, followed by S. aureus, Shigella spp., and Salmonella spp. In this study, the contamination degree of milk by the pathogenic bacteria is utterly worsened at each critical sampling point. High contamination level was observed at milk and fecal samples of cattle and buffaloes, while the least contamination level was observed in trough of lactating animals. The difference in isolation rate across different farms (critical sampling points) is statistically significant in E. coli and S. aureus, as given in Table 1 and Figure 1.

3.2. Antimicrobial Susceptibility of the Bacterial Isolates. Antibiotics were found to have the best efficiency against both Gram-negative and Gram-positive bacteria, according to the antibiogram. Resistance to antibiotics appeared from the environmental E. coli, Salmonella spp., Shigella spp., and S. aureus isolated from teat milk, drinking water, fecal swab, and trough lactating animal. All the 4 bacterial isolates displayed resistance against 15 antibiotics. These are indicative of significant contamination of different resistance rates. The most prevalent organism overall was E. coli, and $S$. aureus was observed with high resistance rate against antibiotics (Tables 2 and 3).

The findings of this investigation clearly reveal that E. coli and S. aureus were resistant to all antimicrobials tested. E. coli isolates had the highest resistance rate, and $S$. aureus isolates were shown to be multidrug resistant (Figure 2). Salmonella spp. and Shigella spp. showed lower resistance rate to all antimicrobials tested (Figure 3).

3.3. Determination of Multiple Antibiotic Resistance Index (MARI) Percentage. Multiple antibiotic resistance index phenotypes were created by dividing the number of antibiotics resistant by the total number of antibiotics tested for isolates that showed resistance to three or more antibiotics (Table 4).

3.4. Resistance Rate with Different Bacterial Isolates. When the zone diameter resistance was observed with 15 different antibiotics against most Gram-positive and Gramnegative bacteria, 15 antibiotics were found resistant for E. coli and S. aureus, for Shigella, 12 antibiotics were found to be resistant, and for Salmonella, 11 antibiotics were found to be resistance, as given in Table 5 .

The mean \pm SD zone areas for the greater resistance for E. coli and S. aureus is already known to be multiresistant, followed by Salmonella and Shigella when the zone areas are for the low resistance, and there was little difference between mean $\pm \mathrm{SD}$ zone areas for $S$. aureus and $E$. coli as given in Table 6.

\section{Discussion}

The small-scale dairy farming is a significant economic sector for the enhancement of agriculture and livelihoods in developing countries [15]. Milk samples, fore and hind's teats, cattle and buffaloes, fecal matter of 60 of dairy resident animals, and 30 of trough lactating waterfowls contained E. coli, Salmonella spp., Shigella spp., and S. aureus. Other researcher found that the practice of dairy animals in open yards and accumulation of their manure lead to the attraction of wild birds into dairy farms [16]. Similar studies isolated identical E. coli strains from excreta of wild birds collected from two dairy farms with $32.5 \mathrm{~km}$ distance apart, on the same sampling time $[17,18]$.

The outcome of our study revealed that 120 of the total samples were contaminated accounting for large proportion. Escherichia coli and Staphylococcus aureus were the most common species in this study. This was followed by E. coli, Salmonella spp., Shigella spp., and S. aureus, with isolation rates of $88(58 \%), 32(21 \%), 44(29 \%)$, and $81(54 \%)$, respectively. In recent time, it was demonstrated that Escherichia coli was the predominant species in healthy 
TABLE 1: Occurrence of isolates bacteria across critical sampling points $(n=150)$ of different samples collected from dairy farm animals.

\begin{tabular}{|c|c|c|c|c|c|c|}
\hline \multirow[b]{2}{*}{$\begin{array}{l}\text { Bacteria } \\
\text { isolated }\end{array}$} & \multirow[b]{2}{*}{$\begin{array}{l}\text { Isolate no. } \\
\qquad(\%)\end{array}$} & \multicolumn{5}{|c|}{ No. of positive samples (\%) } \\
\hline & & $\begin{array}{l}\text { Milk samples, fore and } \\
\text { hinds teats, cattle } \\
\quad(n=30)\end{array}$ & $\begin{array}{l}\text { Milk samples, fore and } \\
\text { hinds teats, buffaloes } \\
\qquad(n=30)\end{array}$ & $\begin{array}{l}\text { Trough lactating } \\
\text { animal }(n=30)\end{array}$ & $\begin{array}{l}\text { Fecal sample, } \\
\text { cattle }(n=30)\end{array}$ & $\begin{array}{l}\text { Fecal sample, } \\
\text { buffaloes }(n=30)\end{array}$ \\
\hline E. coli & $88(58 \%)$ & $21(70 \%)$ & $19(63 \%)$ & $9(30 \%)$ & $20(66 \%)$ & $19(63 \%)$ \\
\hline S. aureus & $81(54 \%)$ & $20(66 \%)$ & $19(63 \%)$ & $2(6 \%)$ & $21(70 \%)$ & $19(63 \%)$ \\
\hline Shigella spp. & $44(29 \%)$ & $12(40 \%)$ & $12(40 \%)$ & $0(0 \%)$ & $11(36 \%)$ & $9(30 \%)$ \\
\hline $\begin{array}{l}\text { Salmonella } \\
\text { spp. }\end{array}$ & $32(21 \%)$ & $6(20 \%)$ & $4(13 \%)$ & $6(20 \%)$ & $8(26 \%)$ & $8(26 \%)$ \\
\hline
\end{tabular}

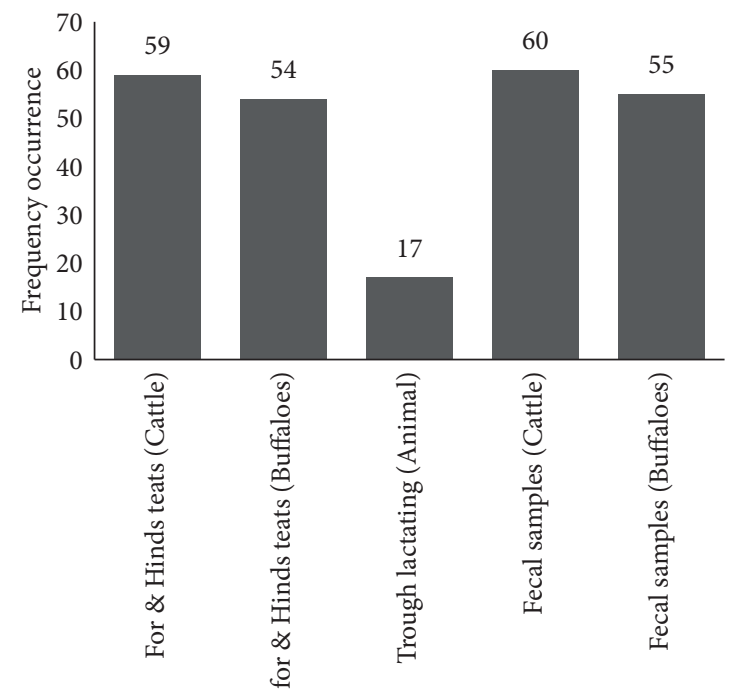

FIGURE 1: Frequency of occurrence isolates from different sampling point percentages.

TABLE 2: Antibiotics sensitivity of Gram-negative bacterial isolates from teat milk samples, drinking water samples, and fecal swabs isolates from cattle's and buffaloes.

\begin{tabular}{|c|c|c|c|c|c|c|c|c|c|}
\hline \multirow{2}{*}{ Antimicrobial } & \multicolumn{3}{|c|}{ E. $\operatorname{coli}(n=88)$} & \multicolumn{3}{|c|}{ Salmonella spp. $(n=32)$} & \multicolumn{3}{|c|}{ Shigella spp. $(n=44)$} \\
\hline & $\mathrm{R}(\%)$ & $\mathrm{I}(\%)$ & S (\%) & $\mathrm{R}(\%)$ & $\mathrm{I}(\%)$ & S (\%) & $\mathrm{R}(\%)$ & $\mathrm{I}(\%)$ & S (\%) \\
\hline $\mathrm{AMC}$ & $50(56.8)$ & $32(37.5)$ & $24(27.2)$ & $1(3.1)$ & $1(3.1)$ & $1(3.1)$ & $16(36.3)$ & $11(25)$ & $8(18.1)$ \\
\hline AMX & $15(22.7)$ & $12(13.6)$ & $21(23.8)$ & $16(50)$ & $1(3.1)$ & $1(3.1)$ & $8(18.1)$ & $8(18.1)$ & $5(11.3)$ \\
\hline AUG & $22(25)$ & $9(10.2)$ & $46(52.2)$ & $0(0)$ & $1(3.1)$ & $1(3.1)$ & $0(0)$ & $6(13.6)$ & $11(25)$ \\
\hline CTX & $17(19.3)$ & $5(5.6)$ & $36(40.9)$ & $2(6.2)$ & $1(3.1)$ & $2(6.2)$ & $9(20.4)$ & $4(9.0)$ & $17(38.6)$ \\
\hline CAZ & $15(17)$ & $2(2.7)$ & $26(29.5)$ & $1(3.1)$ & $1(3.1)$ & $2(6.2)$ & $10(22.7)$ & $6(13.6)$ & $11(25)$ \\
\hline CXM & $19(21.5)$ & $11(12.5)$ & $29(32.9)$ & $1(3.1)$ & $1(3.1)$ & $2(6.2)$ & $9(20.4)$ & $10(22.7)$ & $7(15.9)$ \\
\hline CPX & $23(26.1)$ & $2(2.7)$ & $14(15.9)$ & $0(0)$ & $1(3.1)$ & $2(6.2)$ & $0(0)$ & $10(22.7)$ & $5(11.3)$ \\
\hline $\mathrm{CP}$ & $15(17)$ & $13(14.7)$ & $13(14.7)$ & $3(9.3)$ & $1(3.1)$ & $2(6.2)$ & $10(22.7)$ & 7 (15.9) & $11(25)$ \\
\hline $\mathrm{TE}$ & $12(13.6)$ & $6(6.8)$ & $19(21.5)$ & $1(3.1)$ & $2(6.2)$ & $1(3.1)$ & 8 (18.1) & $8(18.1)$ & $10(22.7)$ \\
\hline GEN & $13(14.7)$ & $3(3.4)$ & $11(12.5)$ & $1(3.1)$ & $2(6.2)$ & $1(3.1)$ & $6(13.6)$ & $4(9.0)$ & 7 (15.9) \\
\hline STR & $12(13.6)$ & $2(2.7)$ & $20(22.7)$ & $0(0)$ & $2(6.2)$ & $1(3.1)$ & $4(9.0)$ & $9(20.4)$ & $11(25)$ \\
\hline ERY & $12(13.6)$ & $2(2.7)$ & $13(14.7)$ & $1(3.1)$ & $2(6.2)$ & $1(3.1)$ & $6(13.6)$ & $9(20.4)$ & $12(27.2)$ \\
\hline CHL & $12(13.6)$ & $2(2.7)$ & $27(30.6)$ & $1(3.1)$ & $1(3.1)$ & $1(3.1)$ & $4(9.0)$ & $4(9.0)$ & $12(27.2)$ \\
\hline NIT & $11(12.5)$ & $8(9)$ & $17(19.3)$ & $1(3.1)$ & $1(3.1)$ & $1(3.1)$ & $8(18.1)$ & $5(11.3)$ & $11(25)$ \\
\hline STX & $14(5.9)$ & $5(5.6)$ & $20(22.7)$ & $1(3.1)$ & $2(6.2)$ & $1(3.1)$ & $0(0)$ & $4(9.0)$ & $11(25)$ \\
\hline
\end{tabular}

AMC, ampicillin; AMX, amoxicillin; AUG, augmentin; CTX, cefotaxime; CAZ, ceftazidime; CXM, cefuroxime; CPX, ciprofloxacin; CP, cefpodoxime; TE, tetracycline; GEN, gentamicin; STR, streptomycin; ERY, erythromycin; CHL, chloramphenicol; NIT, nitrofurantoin; STX, cotrimoxazole.

animals; this finding is also in tandem with the current study [19]. Four bacterial species were prevalent from skin wound samples: E. coli, S. aureus, Salmonella, and Shigella spp. This reported that E. coli, Shigella spp., S. aureus, and Salmonella spp. and their occurrence percentages tandem with the current study [20]. In a similar manner, high rate of 
TABLE 3: Antibiotics sensitivity of Gram-positive bacterial isolates from teat milk samples, drinking water samples, and fecal swabs isolates from cattle's and buffaloes.

\begin{tabular}{lccc}
\hline Antimicrobial & & S. aureus $(n=81)$ & S (\%) \\
\hline AMC & $\mathrm{R}(\%)$ & $\mathrm{I}(\%)$ & $20(24.6)$ \\
AMX & $49(60.4)$ & $32(39.8)$ & $22(27.1)$ \\
AUG & $19(23.4)$ & $5(6.1)$ & $33(40.7)$ \\
CTX & $20(24.6)$ & $5(6.1)$ & $26(32)$ \\
CAZ & $17(20.9)$ & $11(13.5)$ & $29(35.8)$ \\
CXM & $14(17.2)$ & $6(7.4)$ & $19(23.4)$ \\
CPX & $18(22.2)$ & $2(2.4)$ & $20(24.6)$ \\
CP & $23(28.3)$ & $12(14.8)$ & $12(14.8)$ \\
TE & $15(18.5)$ & $6(7.4)$ & $19(23.4)$ \\
GEN & $11(13.5)$ & $3(3.7)$ & $11(13.5)$ \\
STR & $12(14.8)$ & $2(2.4)$ & $20(24.6)$ \\
ERY & $12(14.8)$ & $2(2.4)$ & $20(24.6)$ \\
CHL & $11(13.5)$ & $8(9.8)$ & $28(34.5)$ \\
NIT & $10(12.3)$ & $5(6.1)$ & $17(20.9)$ \\
STX & $13(16)$ & $0.4)$ & $20(24.6)$ \\
\hline AMC & $14(17.2)$ & $(2.4)$ & \\
\hline
\end{tabular}

AMC, ampicillin; AMX, amoxicillin; AUG, augmentin; CTX, cefotaxime; CAZ, ceftazidime; CXM, cefuroxime; CPX, ciprofloxacin; CP, cefpodoxime; TE, tetracycline; GEN, gentamicin; STR, streptomycin; ERY, erythromycin; CHL, chloramphenicol; NIT, nitrofurantoin; STX, cotrimoxazole.

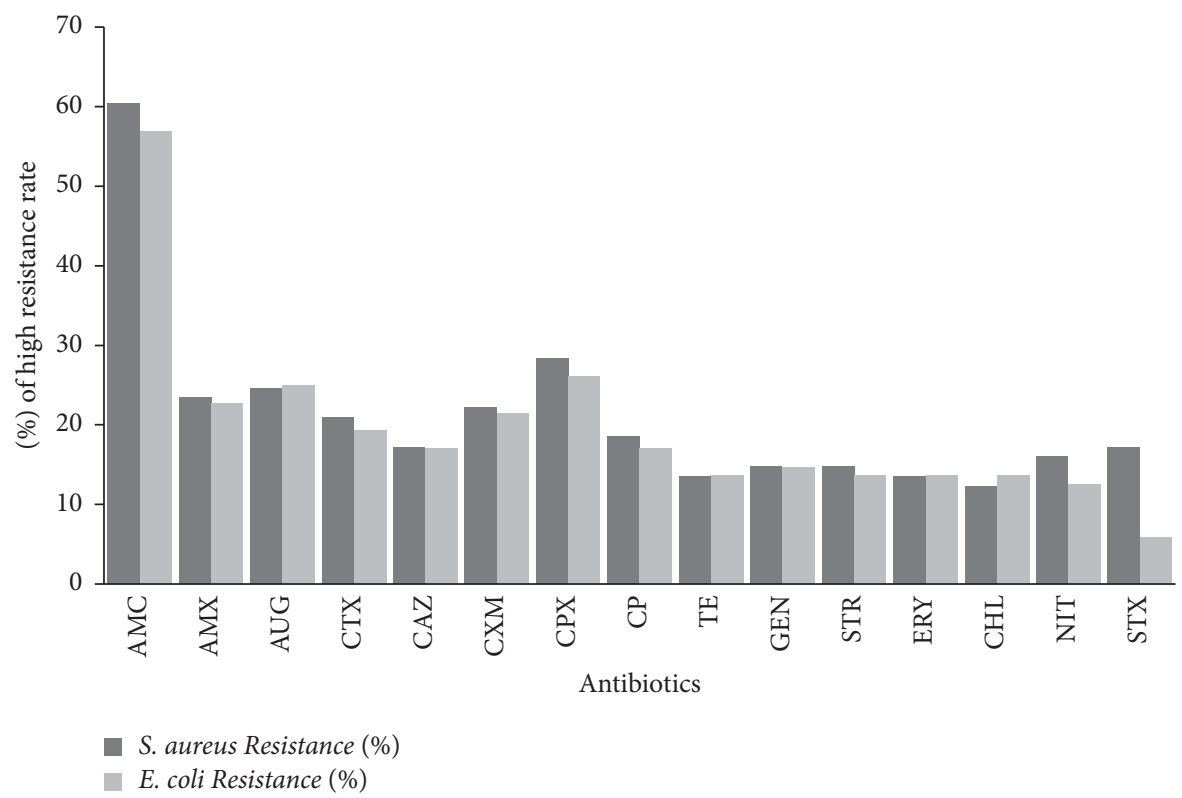

Figure 2: Percentage of high resistance rate of antibiotics isolates in Staphylococcus aureus and Escherichia coli.

Escherichia coli was reported in cows from Jordan [21]. These findings are also consistent with other reports, where Escherichia coli was observed as the predominant species in healthy animals [19]. Various workers throughout world did high rate to isolate the bacterial organisms from wound samples of animals. However, the results of the present figures can be compared with the results of $[20,22,23]$.

Handling of the animals, misuse of antibiotics, and other factors might be responsible for the differences certainly and not only geographical location. Overall, the high prevalence of E. coli and S. aureus occurrence over other isolates can be explained by the members of normal flora in animals; however, occurrence of E. coli, Salmonella spp., Shigella spp., and $S$. aureus is a pointer to high burden that have potential risk to animals and human health.

In this study, the disc diffusion method of detection was employed, previously reported as the method of detection. The major finding in the present study is the presence of multiple drug-resistant E. coli in dairy animals. In present study, ampicillin had the highest resistance rates in $E$. coli (56.8\%), followed by ciprofloxacin $(26.1 \%)$ and augmentin (25\%). Antibiotic resistance among bacteria, particularly Escherichia coli isolated from cattle and other animals, is developing at an alarming rate, according to findings in other studies [24]. Resistance to doxycycline was the strongest in E. coli. In comparison, ampicillin (100\%) and 


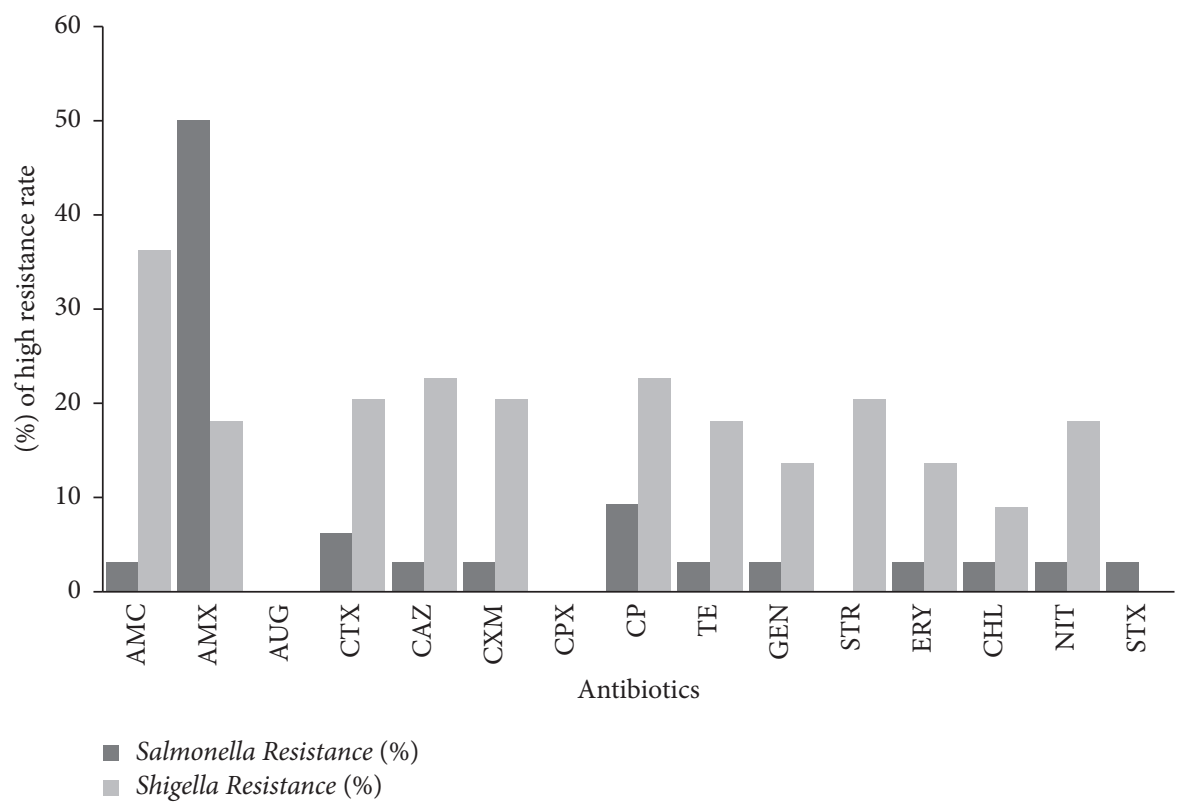

Figure 3: Percentage of high resistance rate of antibiotics isolates in Salmonella spp. and Shigella spp.

TABLE 4: Multidrug resistance indexes (MARIs) of the isolates.

\begin{tabular}{lrrr}
\hline Isolates & List of antibiotics (phenotype) & MARI & $\%$ \\
\hline S. aureus & AMC, AMX, AUG, CTX, CAZ, CXM CPX, CP, TE, GEN, STR, ERY, CHL, NIT, STX & 15 & 12.5 \\
E. coli & AMC, AMX, AUG, CTX, CAZ, CXM CPX, CP, TE, GEN, STR, ERY, CHL, NIT, STX & 15 & 12.5 \\
Salmonella spp. & AMC, AMX, CTX, CAZ CXM, CP, TE, GEN, ERY, CHL, NIT, STX & 12 \\
Shigella spp. & AMC, AMX, CTX, CAZ CXM, CP, TE, GEN, STR, ERY, CHL, NIT & 10 \\
\hline
\end{tabular}

AMC, ampicillin; AMX, amoxicillin; AUG, augmentin; CTX, cefotaxime; CAZ, ceftazidime; CXM, cefuroxime; CPX, ciprofloxacin; CP, cefpodoxime; TE, tetracycline; GEN, gentamicin; STR, streptomycin; ERY, erythromycin; CHL, chloramphenicol; NIT, nitrofurantoin; STX, cotrimoxazole.

TABLE 5: Zone diameters of multidrug that were found resistant against bacterial organisms.

\begin{tabular}{lcccc}
\hline \multirow{2}{*}{ Antimicrobial } & S. aureus & E. coli & Salmonella spp. & Shigella spp. \\
& $\mathrm{R}$ & $\mathrm{R}$ & $\mathrm{R}$ & $\mathrm{R}$ \\
\hline AMC & 49 & 50 & 1 & 16 \\
AMX & 19 & 15 & 16 & 8 \\
AUG & 20 & 22 & 0 & 0 \\
CTX & 17 & 17 & 2 & 9 \\
CAZ & 14 & 15 & 1 & 10 \\
CXM & 18 & 19 & 1 & 9 \\
CPX & 23 & 23 & 0 & 0 \\
CP & 15 & 15 & 3 & 10 \\
TE & 11 & 12 & 1 & 8 \\
GEN & 12 & 13 & 1 & 6 \\
STR & 12 & 12 & 0 & 4 \\
ERY & 11 & 12 & 1 & 6 \\
CHL & 10 & 12 & 1 & 4 \\
NIT & 13 & 11 & 1 & 5 \\
STX & 14 & 14 & 1 & 4 \\
\hline
\end{tabular}

amoxicillin (100\%) had a far greater resistance rate $(42.11 \%)$ [25]. The major finding is the presence of multiple drugresistant $E$. coli in animals to commonly used antibiotics such as ampicillin (95\%), augmentin (91\%), cefotaxime
TABLE 6: Bacterial organisms isolates with different mean and standard division.

\begin{tabular}{lc}
\hline Bacterial isolates & Mean \pm SD \\
\hline S. aureus & $17.2 \pm 9.76$ \\
E. coli & $17.46 \pm 9.75$ \\
Salmonella spp. & $2.63 \pm 9.38$ \\
Shigella spp. & $8.16 \pm 4.68$ \\
\hline
\end{tabular}

$(85 \%)$, tetracycline $(72 \%)$, gentamicin (66\%), and amoxicillin + clavulanic acid (58\%) [26].

In this report, however, the highest rate of resistance to amoxicillin was found in Salmonella spp. (50\%). In previous studies from Ethiopia, several researchers discovered antibiotic-resistant Salmonella isolates from milk $[27,28]$ and also from other countries [29]. Tajbakhsh et al. reported that Salmonella spp. isolates were resistance to ampicillin (42.58\%), tetracycline (42.58\%), and nalidixic acid (78.57\%) [30]. Addis et al. reported a high resistance rate of Salmonella isolates to ampicillin (100\%) [31].

In this study, ampicillin had the highest resistance rate for Shigella spp. (36.3\%), followed by cefpodoxime and ceftazidime (22.7\%). Sanaa et al. found that Shigella isolates from raw milk were responsive to gentamycin $(64.3 \%)$ and 
chloramphenicol (92.1\%), and the strongest antimicrobial resistance pattern was detected against ampicillin and amoxicillin (92.9\% and $92.9 \%)$, followed by penicillin (92.9\%) (42.9\%), in agreement with the outcome [32].

The findings of this investigation clearly demonstrated that $S$. aureus was resistant to all antimicrobials tested, with the exception of ampicillin and ciprofloxacin. These findings suggest that the problem is widely spread and distributed. Furthermore, overall resistance of $S$. aureus isolates to ampicillin, ciprofloxacin, augmentin, amoxicillin, and erythromycin was less than $25 \%$, which is consistent with $\mathrm{Ma}$ et al.' study from a Taiwanese dairy farm. It is probable that these antimicrobials were less resistant since they are not often used in veterinary and possibly human medicine in the study area. Calderón-Jaimes et al. reported that the development of antimicrobial resistance is nearly always as a result of repeated therapeutic and/or indiscriminate use of them that gave similar suggestion [33]. However, the current investigation has revealed that $S$. aureus' resistance to routinely used antimicrobials (penicillin-G and tetracycline) is alarmingly high in the studied area. This is because tetracycline and penicillin are commonly and ineffectively used antimicrobials in animal and human medicine. The findings matched those of previous research conducted in other nations $[34,35]$, suggesting that extended and indiscriminate use of some antimicrobials could lead to the development of resistance. This is in contrast to the findings of [36].

The multiple antibiotic resistance index (MARI) of the isolates recovered in the present study indicates multidrug resistance in nature. The MARI value $>0.2$ is suggesting multidrug resistance due to high-risk application and contamination of antibiotics [37]. An average of 0.8 MARI in this study is higher than the report of [38]. High reported pattern MARI of $0.11-0.78$ is reported from Ghana. These findings demonstrate that the cattle were exposed to multiple classes of antibiotics. This can be explained by the sample size and antibiotic regulation in the study area, among other factors. Many other factors are involved.

When the zone diameters were multidrug resistance (mean $\pm \mathrm{SD}$ ) against bacterial organisms used in the study, it was determined that there was little statistically significant difference. It was determined that $( \pm 9.76$ SD and \pm 9.75 SD) were resistance to $S$. aureus and E. coli, followed by Salmonella and Shigella, when the zone areas for the low resistance are $( \pm 9.38 \mathrm{SD}$ and $\pm 4.86 \mathrm{SD})$. These findings determined that there was a little difference between S. aureus and E. coli. Various workers throughout world did high-rate antibacterial activity against $S$. aureus (zone of inhibition $8.0 \mathrm{~mm}$ ), but less active against $E$. coli [39]. In the study results, $S$. aureus showed $10 \mathrm{~mm}$ zone inhibition, while there was no indication of inhibition against E. coli. The results of the study are consistent with the results of other studies [40]. In addition, on the 5th day of the application, somatic cell increase was observed due to the inflammatory reaction [41].

As a result, we recommend using molecular approaches to characterize these isolates for the presence of antibiotic resistance determinants, which could give data to back up our findings. Because E. coli and S. aureus are commonly found in animals, $S$. aureus found in milk, feces, and water of dairy cows and buffaloes could have come via human transmission, raising doubts about the hygiene standards used.

\section{Conclusion}

The study showed that the different sampling point matter of dairy animals could be considered as a potential risk factor for disseminating pathogenic in dairy animals, leading to contaminating the teat skin of lactating animal's dairy farm. Milking hygiene practices such as washing worker hands, rinsing udder and teats in sanitizing solution, then drying them, followed by effective germicidal teat dip could reduce pathogenic bacterial load on the udder skin. Further research should be carried out to explore other environmental risk factors responsible for intramammary infections within dairy herds.

\section{Data Availability}

The datasets that support the findings of this study are available from the corresponding author upon reasonable request.

\section{Conflicts of Interest}

The authors declare that they have no conflicts of interest.

\section{Acknowledgments}

The work was supported by the earmarked fund for the China Agriculture Research System (CARS-38) and NSFC (31872520). The authors would like to thank professor Jiyu Zhang Ph.D., Lanzhou Institute of Husbandry and Pharmaceutical Sciences, Chinese Academy of Agriculture Sciences, for providing feedback on this manuscript.

\section{References}

[1] T. Mikuš, M. Radeski, L. T. Cziszter et al., "The danube region-on stream with animal welfare assessment in the last 35 Years: a review of research on animal welfare assessment in a multi-lingual area in europe," Journal of Agricultural and Environmental Ethics, vol. 31, no. 4, pp. 511-526, 2018.

[2] M. C. Cantor, H. W. Neave, and J. H. C. Costa, "Current perspectives on the short- and long-term effects of conventional dairy calf raising systems: a comparison with the natural environment," Translational Animal Science, vol. 3, no. 1, pp. 549-563, 2019.

[3] R. Aneja, B. Mathur, R. Chandan, and A. Banerjee, Technology of Indian Milk Products: Handbook on Process Technology Modernization for Professionals, Entrepreneurs and Scientists, Dairy India Yearbook, England, 2002.

[4] A. Fadaei, "Bacteriological quality of raw cow milk in Shahrekord, Iran," Veterinary World, vol. 7, no. 4, pp. 240-243, 2014.

[5] E. Olatunji, I. Ahmed, and U. Ijah, "Evaluation of microbial qualities of skimmed milk (nono) in Nasarawa State, Nigeria," in Proceedings of the 14th Annual Conference of the 
Paediatrics. Association of Nigeria.(ASAN) LAUTECH, Ogbomoso, Nigeria, July 2009.

[6] N. Y. Shpigel, S. Elazar, and I. Rosenshine, "Mammary pathogenic Escherichia coli," Current Opinion in Microbiology, vol. 11, no. 1, pp. 60-65, 2008.

[7] A. Soomro, M. Arain, M. Khaskheli, and B. Bhutto, "Isolation of Escherichia coli from raw milk and milk products in relation to public health sold under market conditions at Tandojam," Pakistan Journal of Nutrition, vol. 1, no. 3, pp. 151-152, 2002.

[8] F. Bouazza, R. Hassikou, F. Ohmani et al., "Hygienic quality of raw milk at Sardi breed of sheep in Morocco," African Journal of Microbiology Research, vol. 6, no. 11, pp. 2768-2772, 2012.

[9] W. L. Claeys, S. Cardoen, G. Daube et al., "Raw or heated cow milk consumption: review of risks and benefits," Food Control, vol. 31, no. 1, pp. 251-262, 2013.

[10] A. E. Van den Bogaard, N. London, C. Driessen, and E. Stobberingh, "Antibiotic resistance of faecal Escherichia coli in poultry, poultry farmers and poultry slaughterers," Journal of Antimicrobial Chemotherapy, vol. 47, no. 6, pp. 763-771, 2001.

[11] R. Laxminarayan, "Bacterial Resistance and the Optimal Use of Antibiotics," 2001.

[12] P. Wayne, Performance Standards for Antimicrobial Susceptibility Testing: Twenty-Seventh Informational Supplement M100-S27, CLSI, Wayne, PA, 2017.

[13] P. Wayne, Clinical and Laboratory Standards Institute, Performance Standards For Antimicrobial Susceptibility Testing, Wayne, PA, USA, 2011.

[14] P. H. Krumperman, "Multiple antibiotic resistance indexing of Escherichia coli to identify high-risk sources of fecal contamination of foods," Applied and Environmental Microbiology, vol. 46, no. 1, pp. 165-170, 1983.

[15] J. J. McDermott, T. F. Randolph, and S. J. Staal, "The economics of optimal health and productivity in smallholder livestock systems in developing countries," Revue Scientifique et Technique de l'OIE, vol. 18, no. 2, pp. 399-424, 1999.

[16] K. M. Fahim, E. Ismael, H. S. Khalefa, H. S. Farag, and D. A. Hamza, "Isolation and characterization of E. coli strains causing intramammary infections from dairy animals and wild birds," International journal of veterinary science and medicine, vol. 7, no. 1, pp. 61-70, 2019.

[17] N. Cernicchiaro, D. Pearl, S. McEwen et al., "Association of wild bird density and farm management factors with the prevalence of E. coli $\mathrm{O} 157$ in dairy herds in Ohio," Zoonoses and public health, vol. 59, no. 5, pp. 320-329, 2009.

[18] J. Van Donkersgoed, J. Berg, A. Potter et al., "Environmental sources and transmission of Escherichia coli O157 in feedlot cattle," Canadian Veterinary Journal, vol. 42, no. 9, p. 714, 2001.

[19] N. Oloso, S. Fagbo, M. Garbati et al., "Antimicrobial resistance in food animals and the environment in Nigeria: a review," International Journal of Environmental Research and Public Health, vol. 15, no. 6, p. 1284, 2018.

[20] S. Arbab, H. Ullah, W. Weiwei et al., "Comparative study of antimicrobial action of aloe vera and antibiotics against different bacterial isolates from skin infection," Veterinary Medicine and Science, vol. 7, no. 5, pp. 2061-2067, 2021.

[21] D. Zhang, Z. Zhang, C. Huang et al., "The phylogenetic group, antimicrobial susceptibility, and virulence genes of Escherichia coli from clinical bovine mastitis," Journal of Dairy Science, vol. 101, no. 1, pp. 572-580, 2018.

[22] S. Arbab, R. Buriro, S. U. Bhugio et al., "Antimicrobial properties of aloe vera gel extracts against bacterial isolates from wound of donkey," Pakistan Journal of Zoology, vol. 52, no. 6,2020 .

[23] S. Arbab, R. S. Buriro, H. Ullah et al., "Comparison of antibacterial activity of Ciprofloxacin and Cephalexin against Some common bacterial Species isolates from donkey wounds around the vicinity of Tandojam Sindh Pakistan," Pure and Applied Biology, vol. 10, no. 4, pp. 1095-1103, 2021.

[24] A. O. Ogunleye, M. A. Oyekunle, and A. O. Sonibare, "Multidrug resistant Escherichia coli isolates of poultry origin in Abeokuta, South Western Nigeria," Veterinarski Arhiv, vol. 78, no. 6, pp. 501-509, 2008.

[25] H. Thaker, M. Brahmbhatt, and J. Nayak, "Study on occurrence and antibiogram pattern of Escherichia coli from raw milk samples in Anand," Veterinary World, vol. 5, no. 9, p. 556, 2012.

[26] S. Arbab, H. Ullah, X. Wei, W. Wang, S. U. Ahmad, and J. Zhang, "Drug resistance and susceptibility testing of Gram negative bacterial isolates from healthy cattle with different $\hat{\mathrm{I}}^{2} \hat{\mathrm{a}} €$ ”Lactam resistance Phenotypes from Shandong province China," Brazilian Journal of Biology, vol. 83, 2021.

[27] B. Molla, D. Alemayehu, and W. Salah, "Sources and distribution of Salmonella serotypes isolated from food animals, slaughterhouse personnel and retail meat products in Ethiopia: 1997-2002," The Ethiopian Journal of Health Development, vol. 17, no. 1, pp. 63-70, 2003.

[28] H. Mekonnen, S. Workineh, M. Bayleyegn, A. Moges, and K. Tadele, "Antimicrobial susceptibility profiles of mastitis isolates from cows in three major Ethiopian dairies," Revue de Medecine Veterinaire, vol. 156, no. 7, p. 391, 2005.

[29] D. G. White, S. Zhao, R. Sudler et al., "The isolation of antibiotic-resistant Salmonella from retail ground meats," New England Journal of Medicine, vol. 345, no. 16, pp. 1147-1154, 2001.

[30] F. Tajbakhsh, E. Tajbakhsh, M. Momeni, E. Rahimi, and R. Sohrabi, "Occurrence and antibiotic resistance of Salmonella spp isolated from raw cow's milk from shahahrekord," Iran. Inter. J. Microbiol. Res, vol. 3, pp. 242-245, 2012.

[31] Z. Addis, N. Kebede, Z. Worku, H. Gezahegn, A. Yirsaw, and T. Kassa, "Prevalence and antimicrobial resistance of Salmonella isolated from lactating cows and in contact humans in dairy farms of Addis Ababa: a cross sectional study," BMC Infectious Diseases, vol. 11, no. 1, pp. 222-227, 2011.

[32] A. A. Reda, B. Seyoum, J. Yimam, S. Fiseha, and V. Jean-Michel, "Antibiotic susceptibility patterns of Salmonella and Shigella isolates in Harar, Eastern Ethiopia," Journal of Infectious Diseases and Immunity, vol. 3, no. 8, pp. 134-139, 2011.

[33] E. Calderón-Jaimes, L. E. E. de los Monteros, and R. Avila-Beltrán, "Epidemiology of drug resistance: the case of Staphylococcus aureus and coagulase-negative staphylococci infections," Salud Publica de Mexico, vol. 44, no. 2, pp. 108112, 2002.

[34] J. El-Jakee, A. S. Nagwa, M. Bakry, S. A. Zouelfakar, E. Elgabry, and W. El-Said, "Characteristics of Staphylococcus aureus strains isolated from human and animal sources," American-Eurasian Journal of Agricultural \& Environmental Sciences, vol. 4, no. 2, pp. 221-229, 2008.

[35] M. Edward, K. Anna, K. Michal, L. Henryka, and K. Krystyna, "Antimicrobial susceptibility of Staphylococci isolated from mastitic cows," Bulletin of the Veterinary Institute, vol. 46, pp. 289-294, 2002.

[36] Y. P. Ma, S. K. Chang, and C. C. Chou, "Characterization of bacterial susceptibility isolates in sixteen dairy farms in 
Taiwan," Journal of Dairy Science, vol. 89, no. 12, pp. 4573-4582, 2006.

[37] A. Joseph, M. Odimayo, L. Olokoba, A. Olokoba, and G. Popoola, "Multiple antibiotic resistance iIndex of EscherichiaColi isolates in a tertiary hospital in south-west Nigeria," Medical Journal of Zambia, vol. 44, no. 4, pp. 225-232, 2017.

[38] T. P. Mthembu, O. T. Zishiri, and M. E. El Zowalaty, "Molecular detection of multidrug-resistant Salmonella isolated from livestock production systems in South Africa," Infection and Drug Resistance, vol. 12, pp. 3537-3548, 2019.

[39] S. Singh, M. Malhotra, and D. K. Majumdar, "Antibacterial activity of ocimum sanctum 1 . fixed oil," Indian Journal of Experimental Biology, vol. 43, 2005.

[40] A. K. Bhatia, A. Kumar, A. Goel, A. Gupta, and A. Rahal, "Antibacterial activity of hot aqueous extract of Ocimum sanctum leaves against common bacterial pathogens of animals," Pharma Science Monitor, vol. 3, no. 3, 2013.

[41] H. Aydin, "Phytotherapy with O. sanctum and O. onites in cows with subclinical mastitis," Kocatepe Veterinary Journal, vol. 13, no. 4, pp. 420-425, 2020. 